Article

\title{
Performance Improvement of a Nonvolatile UV TD Sensor Using SAHAOS with a High Temperature Annealed, Partially Nano-Crystallized Trapping Layer
}

\author{
Wen-Ching Hsieh \\ Opto-Electronic System Engineering Department, Minghsin University of Science and Technology, \\ Xinfeng 30401, Taiwan; wchsieh@must.edu.tw; Tel.: +886-936-341-710
}

Received: 31 January 2019; Accepted: 26 March 2019; Published: 1 April 2019

\begin{abstract}
This study shows that a silicon-aluminum oxide-hafnium aluminum oxide-silicon oxide-silicon capacitor device with a high temperature pre-metal-anneal-treated and partially-nanocrystallized hafnium aluminum oxide, (hereafter PNC-SAHAOS) can successfully increase the performance of a nonvolatile ultraviolet radiation total dose (hereafter UV TD) sensor. The experimental results show that the UV-induced threshold voltage $V_{T}$ shift of PNC-SAHAOS was $10 \mathrm{~V}$ after UV TD $100 \mathrm{~mW} \cdot \mathrm{s} / \mathrm{cm}^{2}$ irradiation. The UV-induced charge density of PNC-SAHAOS is almost eight times that of amorphous silicon-aluminum oxide-silicon nitride-silicon dioxide-silicon SANOS. Moreover, the charge fading rate of ten-years retention on PNC-SAHAOS, even at $85^{\circ} \mathrm{C}$, is below $10 \%$. At $85^{\circ} \mathrm{C}$, the charge fading rate of ten-years retention on amorphous SANOS is almost twice that on PNC-SAHAOS. These results strongly suggest that PNC-SAHAOS could be the most promising candidate for next-generation nonvolatile UV TD sensor technology.
\end{abstract}

Keywords: nano; SOHOS; UV; TD; sensor

\section{Introduction}

Ultraviolet (UV) radiation is used in many fields and plays an important role in fields such as optical sensing, industrial and commercial testing, biomedical technology, medical diagnosis and treatment, industrial manufacturing, semiconductor manufacturing, defense technology, and environmental protection. In the future, the UV TD measurement market will be huge, but there is no good way to make it popular.

Conventional semiconductor radiation intensity sensing elements are semiconductor photodiodes (PIN), [1] and conventional radiation total dose (TD) sensing elements are thermal luminescent dosimeters (TLD) [2], but they still have some drawbacks that need to be improved. The PIN device has the advantages of a small size, light weight, and high sensitivity. However, the PIN component is a radiation intensity sensing component, not a radiation TD sensing component. The TLD component is a non-volatile radiation TD sensing component, but the TLD's TD record is not easily readable, and reading of the TLD's TD record requires a sophisticated thermal illumination detection system. Recently, metal-oxide-semiconductor- (MOS) type radiation dose sensors have been studied. However, the radiation dose record of these MOS-type radiation dose sensors cannot be saved for a long period, even at room temperature $[3,4]$. The silicon-silicon oxide-silicon nitride-silicon oxide-silicon-(SONOS) type nonvolatile memory is chosen as one of the most promising candidates for next generation nonvolatile memory due to its coupling-free and MOS-like structure. However, a SONOS-like capacitor device has also been shown to be suitable for nonvolatile UV TD sensor applications [5]. UV radiation causes a charging effect of the SONOS device, and the UV-induced charging effect of the SONOS is associated with UV TD. The UV TD information can be permanently stored and accumulated in the 
non-volatile SONOS device. Even after 10 years of retention, the UV-induced charge of the SONOS-like device maintains good reliability at room temperature. For SONOS-type non-volatile UV TD sensors, the electrons in the capture layer find it difficult to escape to the control gate due to the relatively high barrier height of the thick $\mathrm{SiO}_{2}$ barrier oxide. Therefore, UV-induced negative charges are permanently accumulated and stored in the capture layer [5].

In advanced processes, high-k materials exhibit a superior performance compared to standard silicon nitride as a charge trap layer for SONOS-type nonvolatile memories due to their scalability and low voltage applications. A silicon-silicon dioxide-hafnium oxide-silicon dioxide-silicon- (SOHOS) like capacitor device has also been shown to be suitable for nonvolatile UV TD sensor applications in previous studies [6]. However, the improvement of the UV-inductive charging response performance and charge retention reliability for SOHOS-like capacitor UV TD sensors have not been well-studied. In this study, a high temperature pre-metal-annealing (PMA) treated silicon-aluminum oxide-hafnium aluminum oxide-silicon oxide-silicon capacitor device with a partially nanocrystallized trapping layer (hereafter PNC-SAHAOS) is proposed as an improved nonvolatile UV TD sensor. The performance of some devices, such as non-volatile UV TD sensors, including silicon-aluminum oxide-silicon nitride-silicon dioxide-silicon (SANOS) and silicon-aluminum oxide-hafnium aluminum oxide-silicon oxide-silicon capacitor devices (hereafter SAHAOS) with different crystal structure trapping layers, is compared. The results show that the PNC-SAHAOS device can significantly improve the UV-inductive charging response and charge retention characteristic of the UV TD sensor in this study. Table 1 is a comparison of the UV sensors described in this paragraph.

Table 1. Comparison of UV sensors.

\begin{tabular}{|c|c|c|c|}
\hline $\begin{array}{l}\text { Sensor Device } \\
\text { Abbreviation }\end{array}$ & $\begin{array}{l}\text { Device Materials } \\
\text { Composition }\end{array}$ & Characterization & Reference \\
\hline PIN & $\mathrm{SiC}$ & $\begin{array}{l}\text { Cannot measure UV TD, only } \\
\text { can measure UV intensity }\end{array}$ & [1] Sze, S.M. 2006. \\
\hline TLD & $\mathrm{Er}_{2} \mathrm{O}_{3}$ doped $\mathrm{ZrO}_{2}$ & $\begin{array}{l}\text { UV TD record is not easily } \\
\text { readable }\end{array}$ & [2] Hsien, W.C. 1994. \\
\hline MOS & $\mathrm{Si}-\mathrm{SiO}_{2}-\mathrm{Si}$ & $\begin{array}{l}\text { Stability with time after } \\
\text { irradiation is very bad }\end{array}$ & $\begin{array}{l}\text { [3] Pejović, M.M. } 2016 . \\
\text { [4] Ho, W.S. } 2008 .\end{array}$ \\
\hline SONOS & $\begin{array}{c}\text { O doped } \\
\mathrm{Si}_{-} \mathrm{SiO}_{2}-\mathrm{Si}_{3} \mathrm{~N}_{4}-\mathrm{SiO}_{2}-\mathrm{Si}\end{array}$ & $\begin{array}{l}\text { Sensitivity to irradiation and } \\
\text { stability with time after } \\
\text { irradiation can been improved }\end{array}$ & [5] Jong, F.C. 2018. \\
\hline F-SOHOS & $\begin{array}{c}\text { F doped } \\
\mathrm{Si}-\mathrm{SiO}_{2}-\mathrm{HfO}_{2}-\mathrm{SiO}_{2}-\mathrm{Si}\end{array}$ & $\begin{array}{l}\text { Sensitivity to irradiation and } \\
\text { stability with time after } \\
\text { irradiation can been improved }\end{array}$ & [6] Hsien, W.C. 2018. \\
\hline PNC-SAHAOS & $\begin{array}{c}1000{ }^{\circ} \mathrm{C} / 1100{ }^{\circ} \mathrm{C} \mathrm{PMA} \\
\mathrm{Si}_{-} \mathrm{Al}_{2} \mathrm{O}_{3}-\mathrm{HfAlO}-\mathrm{SiO}_{2}-\mathrm{Si}\end{array}$ & $\begin{array}{l}\text { Sensitivity to irradiation and } \\
\text { stability with time after } \\
\text { irradiation are very good }\end{array}$ & This paper. \\
\hline
\end{tabular}

The author of this paper has proposed a mechanism for UV-induced charging in a SAHAOS/SANOS UV TD sensor. The application of both UV and positive gate voltage (hereafter PGV) to the SAHAOS/SANOS capacitor device at the same time is necessary for the writing of UV TD information. UV radiation induced the ionized electron-hole pairs in the silicon substrate of the SAHAOS/SANOS capacitor device. The survival yield of UV-induced electron-hole pairs depends on the PGV of the SAHAOS/SANOS device, due to the easy recombination of UV-induced electron-hole pairs [7]. These UV-induced charges are swept over the $\mathrm{Si}_{-} \mathrm{SiO}_{2}$ potential barrier by an electric field of the SAHAOS/SANOS device, and injected into the hafnium aluminum oxide (HfAlO) trapping layer, and some of these charges are captured by the $\mathrm{HfAlO} / \mathrm{Si}_{3} \mathrm{~N}_{4}$ trapping layer. The accumulation of UV-induced charges changes the $V_{T}$ of the SAHAOS/SANOS device, and the UV-induced threshold voltage $\mathrm{V}_{\mathrm{T}}$ shift depends on the UV TD absorbed by the SAHAOS/SANOS 
device. However, the trapped UV-induced charge finds it difficult to escape to the control gate owing to the thick and relatively large barrier height of the $\mathrm{SiO}_{2}$ blocking oxide. Finally, the trapped UV-induced charges are permanently accumulated in the trapping layers of the SAHAOS/SANOS capacitor device. In order to erase the UV TD data information in the SAHAOS/SANOS UV TD sensor, a negative gate voltage (hereafter NGV) is applied on SAHAOS/SANOS to erase the UV inductive-negative-charge in the HfAlO/ $\mathrm{Si}_{3} \mathrm{~N}_{4}$ capture layer and restore the SAHAOS/SANOS UV-TD-sensor to its original pre-irradiated state. This is the UV-induced charging, discharging, and charge retention process in the nonvolatile SAHAOS/SANOS UV TD sensor. In Figure 1a, the cross-sectional view of the nonvolatile SAHAOS/SANOS UV TD sensor is shown. Moreover, the UV-induced charge generation and capture states of the nonvolatile SAHAOS/SANOS UV TD sensor are shown in Figure 1b.

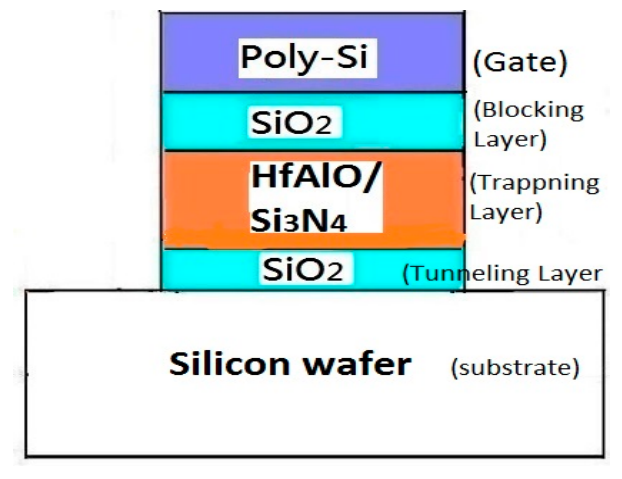

(a)

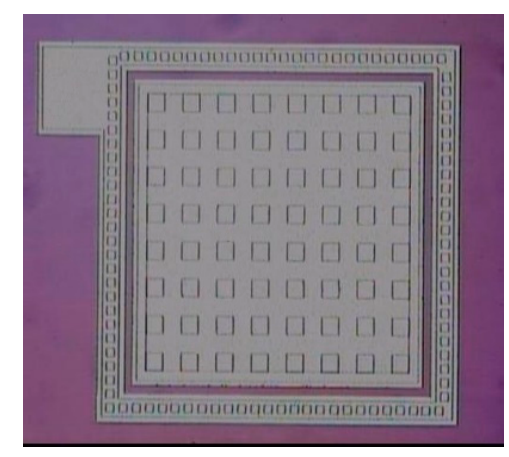

(c)

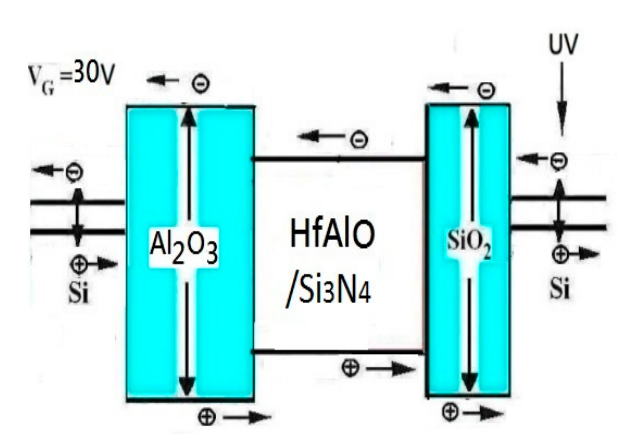

(b)

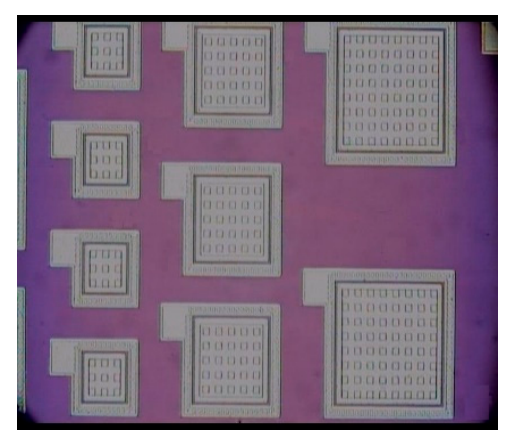

(d)

Figure 1. (a) Cross-sectional view of SAHAOS/SANOS capacitor device; (b) UV-induced charge generation and capture in SAHAOS/SANOS capacitor. (c) OM image of SAHAOS/SANOS capacitor with an area of $100 \times 100 \mu \mathrm{m}^{2}$. (d) OM image of SAHAOS/SANOS capacitors with an area of $100 \times 100 \mu \mathrm{m}^{2}, 200 \times 200 \mu \mathrm{m}^{2}$, and $300 \times 300 \mu \mathrm{m}^{2}$.

\section{Experimental Section}

\subsection{Sensor Fabrication}

To compare the nonvolatile UV TD sensor performance, silicon-aluminum oxide-hafnium aluminum oxide-silicon oxide-silicon (hereafter SAHAOS) with different temperature PMA treatment and standard silicon-aluminum oxide-silicon nitride-silicon dioxide-silicon (SANOS) capacitor devices were prepard for this study. The SAHAOS/SANOS (SONOS-like) devices are five-layer structures in this study: (1) Substrate: SAHAOS/SANOS capacitor structures were fabricated on p-type $\mathrm{Si}<100>$ substrate with a resistivity of $15-25 \mathrm{ohm}-\mathrm{cm}$; (2) charge tunneling layer: the silicon oxide $\mathrm{SiO}_{2}(3 \sim 7 \mathrm{~nm})$ was used for the tunneling oxide; (3) charge storage layer: hafnium aluminum 
oxide (HfAlO) and silicon nitride $\left(\mathrm{Si}_{3} \mathrm{~N}_{4}\right)$ films $(50 \sim 150 \mathrm{~nm})$ were deposited as the charge-trapping oxide; (4) charge blocking layer: aluminum oxide $\mathrm{Al}_{2} \mathrm{O}_{3}(5 \sim 15 \mathrm{~nm})$ was deposited as the blocking oxide; and (5) gate electrode: poly silicon $\mathrm{Si}(100 \sim 400 \mathrm{~nm})$ was used for the gate material.

\subsection{Sensor Fabrication}

There are five fabrication steps for the five-layers-structure SONOS-like devices used in this study: (1) Tunneling oxide: the tunneling oxide $\mathrm{SiO}_{2}$ was thermally grown at $925^{\circ} \mathrm{C}$ by an advanced clustered vertical furnace (ASM A-400) as tunneling oxide for SAHAOS and SANOS devices; (2) trapping oxide: after the tunneling oxide formation, hafnium aluminum oxide HfAlO films were deposited by a metal organic chemical vapor deposition MOCVD system (AIXTRON Tricent 800016) at 400 550 ${ }^{\circ} \mathrm{C}$ as the charge-trapping layers. There were two precursors used for $\mathrm{HfAlO}$ films deposition: $\mathrm{Hf}\left[\mathrm{OC}\left(\mathrm{CH}_{3}\right)_{3}\right]_{4}$ (Sigma-Aldrich, Inc.) and aluminum isopropoxide $\mathrm{Al}\left(\mathrm{OC}_{3} \mathrm{H}_{7}\right)_{3}$ (Sigma-Aldrich, Inc.). By controlling the mixing ratio of the two precursors during the deposition process, the $\mathrm{Al}$ composition ratio in HfAlO is about $10 \% \sim 40 \%$. For standard SANOS devices, after the tunneling oxide was formed, silicon nitride $\mathrm{Si}_{3} \mathrm{~N}_{4}$ (hereafter, nitride) was deposited as the charge-trapping layer by low-pressure chemical vapor deposition LPCVD (SVCS Furnace system); (3) blocking oxide: for the top oxide of SAHAOS/SANOS, the aluminum isopropoxide precursor $\mathrm{Al}\left(\mathrm{OC}_{3} \mathrm{H}_{7}\right)_{3}$ (Sigma-Aldrich, Inc.) was used for $\mathrm{Al}_{2} \mathrm{O}_{3}$ film deposition by MOCVD; (4) PMA: the pre-metal annealing (PMA) at different temperatures was treated with a rapid thermal annealing (RTA) process in $\mathrm{N}_{2}$ ambient (KORONA RTP 800) after the gate dielectric deposition for the SAHAOS/SANOS device; (5) gate electrode: the poly silicon (200-400 nm) was formed by low-pressure chemical vapor deposition LPCVD (ASM Vertical Furnace system) as the control gate material after the PMA process for the SAHAOS/SANOS device. In Table 2, the various SAHAOS devices prepared with various PMA temperature conditions are listed. To compare the UV TD nonvolatile sensor performance for SAHAOS devices with different PMA temperatures and SANOS, three types of SAHAOS with PMA at different temperatures and one SANOS were prepared: (1) standard SANOS with $900^{\circ} \mathrm{C} 30$ s PMA (STD-SANOS); (2) SAHAOS with $900^{\circ} \mathrm{C} 30$ s PMA (hereafter SAHAOS-T1); (3) SAHAOS with $1000^{\circ} \mathrm{C} 30$ s PMA (hereafter SAHAOS-T2); and (4) SAHAOS with $1100{ }^{\circ} \mathrm{C} 5 \mathrm{~s}$ PMA (hereafter SAHAOS-T3). The poly silicons (100-400 nm) were formed by low-pressure chemical vapor deposition (LPCVD) as the control gate. Aluminum Al was sputtered by a Duratek sputter machine on the bottom of the Si substrate to form an ohmic contact. In this study, three types of SAHAOS device and one SANOS capacitor device have the same thickness of the tunneling oxide, trapping oxide, and blocking oxide layer for the nonvolatile UV TD sensor performance comparison.

Table 2. SAHAOS devices prepared with various PMA processes.

\begin{tabular}{ccccc}
\hline Split & T1 & T2 & T3 & N \\
\hline PMA temperature $\left({ }^{\circ} \mathrm{C}\right)$ & 900 & 1000 & 1100 & 900 \\
\hline PMA time $(\mathrm{s})$ & 30 & 30 & 5 & 30 \\
\hline Trapping Layer & HfAlO & HfAlO & HfAlO & $\mathrm{Si}_{3} \mathrm{~N}_{4}$ \\
\hline
\end{tabular}

\subsection{Sensor UV TD Information Measurement}

There are three steps for the SONOS-like nonvolatile sensor UV TD information measurement in this study: (1) Reset record: prior to writing of the UV TD information, a negative gate voltage $(\mathrm{NGV}) \mathrm{V}_{\mathrm{G}}=-40 \mathrm{~V}$ is forced on the SAHAOS and SANOS capacitor device to release the trapped native negative charge from the HfAlO and $\mathrm{Si}_{3} \mathrm{~N}_{4}$, and the SAHAOS and SANOS capacitor devices are erased to a null state; (2) writing record: during the writing of UV TD information, both UV and positive gate bias (PGV) are applied to the SAHAOS and SANOS capacitor devices at the same time. The CNI MLL-III-405 UV LED with a $405 \mathrm{~nm}$ wavelength is used for the UV radiation source. Table 3 presents a list of various UV radiation and various PGV conditions applied simultaneously on the 
SAHAOS and SANOS capacitor devices; (3) reading record: the $\mathrm{V}_{\mathrm{T}}$ variation can be calculated from the $\mathrm{C}_{\mathrm{G}}-\mathrm{V}_{\mathrm{G}}$ curves shifting after UV TD irradiation. The gate capacitance vs. various gate voltages $\left(\mathrm{C}_{\mathrm{G}}-\mathrm{V}_{\mathrm{G}}\right)$ curves were measured by a HP4284 parameter analyzer at room temperature before and after UV TD irradiation. The gate leakage current vs. gate voltage $\left(\mathrm{I}_{\mathrm{G}}-\mathrm{V}_{\mathrm{G}}\right)$ curves for an SAHAOS and SANOS capacitor device were measured at room temperature using a computer-controlled Agilent HP4156A parameter analyzer before and after UV TD irradiation.

Table 3. The list of various UV TD and PGV conditions applied simultaneously on SAHAOS.

\begin{tabular}{ccc}
\hline Symbol & UV TD $\left(\mathbf{m W} \cdot \mathbf{s} / \mathrm{cm}^{2}\right)$ & PGV (V) \\
\hline U0G0 & $0 \mathrm{~mW} \cdot \mathrm{s} / \mathrm{cm}^{2}$ & $0 \mathrm{~V}$ \\
U100G5 & $100 \mathrm{~mW} \cdot \mathrm{s} / \mathrm{cm}^{2}$ & $5 \mathrm{~V}$ \\
U100G10 & $100 \mathrm{~mW} \cdot \mathrm{s} / \mathrm{cm}^{2}$ & $10 \mathrm{~V}$ \\
U100G20 & $100 \mathrm{~mW} \cdot \mathrm{s} / \mathrm{cm}^{2}$ & $20 \mathrm{~V}$ \\
U100G30 & $100 \mathrm{~mW} \cdot \mathrm{s} / \mathrm{cm}^{2}$ & $30 \mathrm{~V}$ \\
\hline
\end{tabular}

\subsection{Sensor Material Analysis}

There are three steps for sensor material analysis in this study: (1) OM: Figure 1c,d show the optical microscope $(\mathrm{OM})$ top view image of an SAHAOS and SANOS capacitor's pattern; (2) TEM: in this paper, transmission electron microscopy (TEM) (JEOL JEM-2010F) was used for HfAlO crystallization analysis of the various SAHAOS devices prepared with various PMA temperature conditions; (3) XRD: X-ray diffraction analysis (XRD) (PANalytical X'Pert Pro) was used for temperature-dependent crystallization analysis of various HfAlO films prepared with various PMA temperature conditions. Figure 2 shows the flow including the experimental and simulation approach.

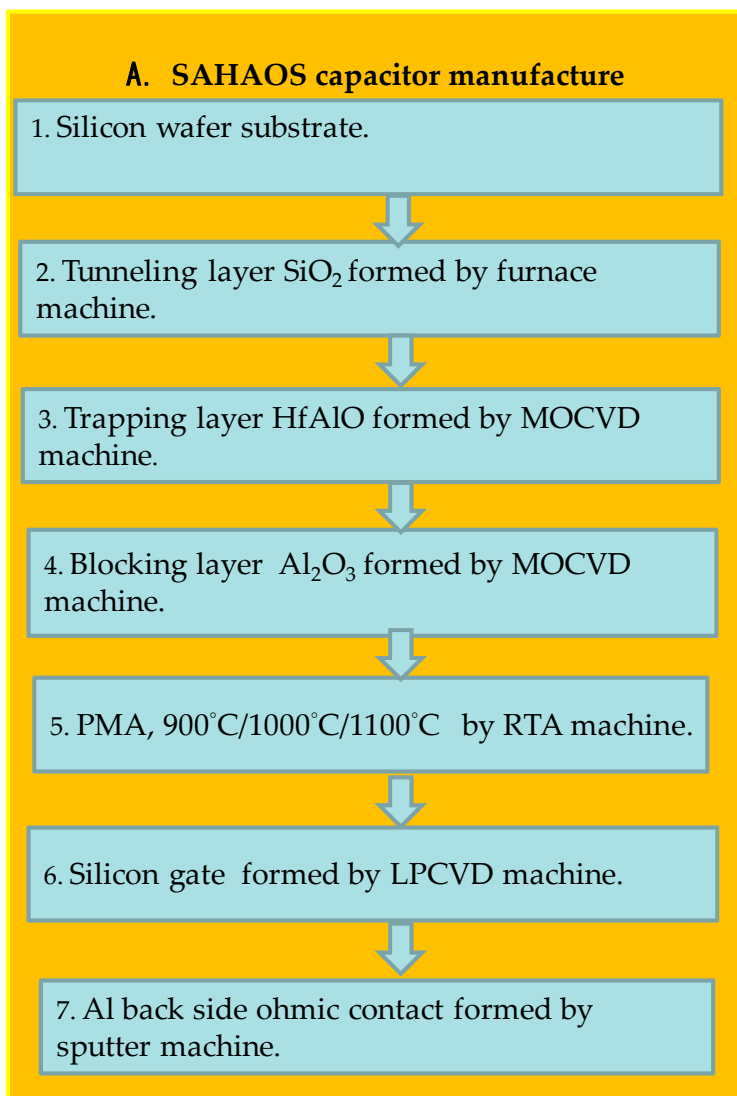

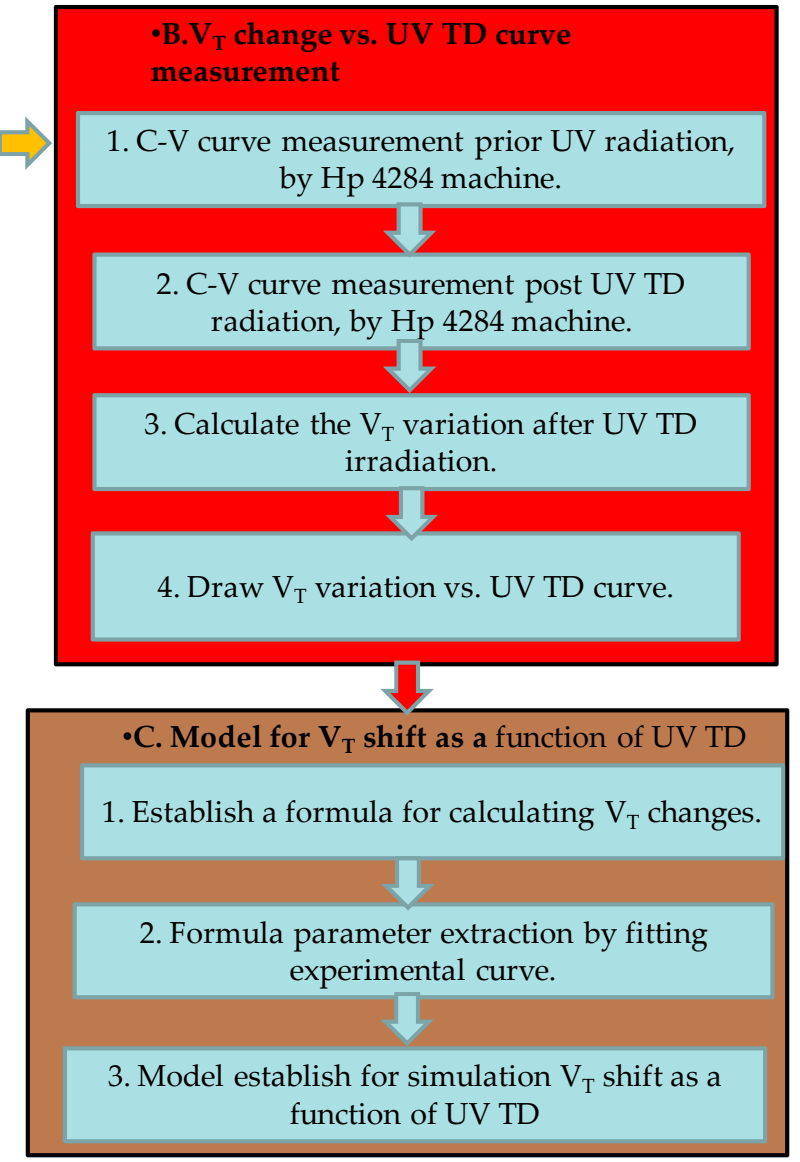

Figure 2. Experimental and simulation approach. 


\section{Results}

\subsection{UV-Induced $V_{T}$ Shift in SAHAOS}

Figure 3a illustrates a $\mathrm{C}_{\mathrm{G}}-\mathrm{V}_{\mathrm{G}}$ curve for an SAHAOS-T3 capacitor before UV irradiation. Figure $3 b$ demonstrates a $C_{G}-V_{G}$ curve for a post-UV-irradiated SAHAOS-T3 capacitor device after $100 \mathrm{~mW} \cdot \mathrm{s} / \mathrm{cm}^{2} \mathrm{UV}$ irradiation under PGV $30 \mathrm{~V}$. The $\mathrm{C}_{\mathrm{G}}-\mathrm{V}_{\mathrm{G}}$ curve of the SAHAOS-T3 capacitor shifted to the right after UV TD up to $100 \mathrm{~mW} \cdot \mathrm{s} / \mathrm{cm}^{2}$ at PGV $30 \mathrm{~V}$, as illustrated in Figure $3 \mathrm{~b}$.

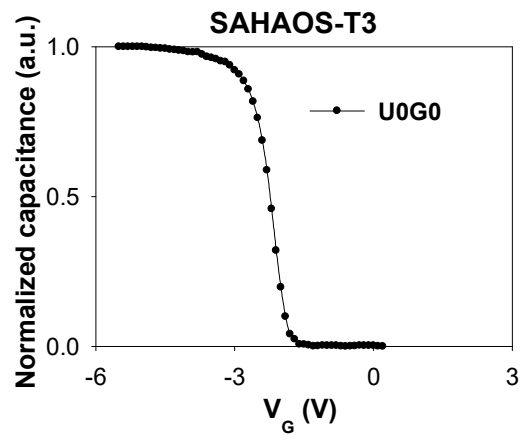

(a)

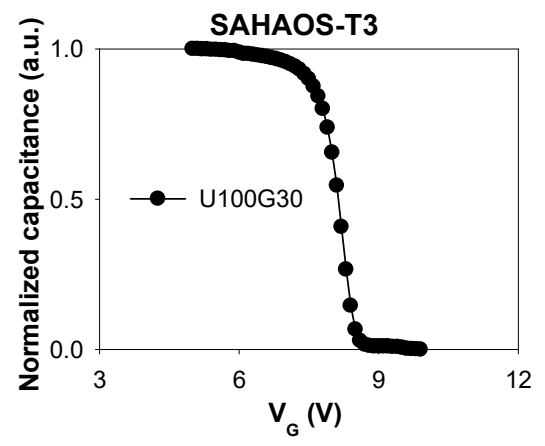

(b)

Figure 3. $\mathrm{C}_{\mathrm{G}}-\mathrm{V}_{\mathrm{G}}$ curve for an SAHAOS-T3 device (a) before UV irradiation; (b) after $100 \mathrm{~mW} \cdot \mathrm{s} / \mathrm{cm}^{2}$ UV TD irradiation at PGV $30 \mathrm{~V}$.

The $\mathrm{V}_{\mathrm{T}}$ increase as a function of UV TD for the SAHAOS-T3 device at $30 \mathrm{~V}$ PGV is illustrated in Figure $4 \mathrm{a}$. Consistent with previous studies, the increase in $\mathrm{V}_{\mathrm{T}}$ in SAHAOS-T3 was associated with an increase in UV TD, but when UV TD was greater than $30 \mathrm{~mW} \cdot \mathrm{s} / \mathrm{cm}^{2}, \mathrm{~V}_{\mathrm{T}}$ increased more slowly [6]. For the SAHAOS-T3 device, the dependence of the $\mathrm{V}_{\mathrm{T}}$ shiftting on UV TD at PGV $30 \mathrm{~V}$ is more significant than that at PGV $20 \mathrm{~V}$, as shown in Figure $4 \mathrm{a}, \mathrm{b}$, respectively.

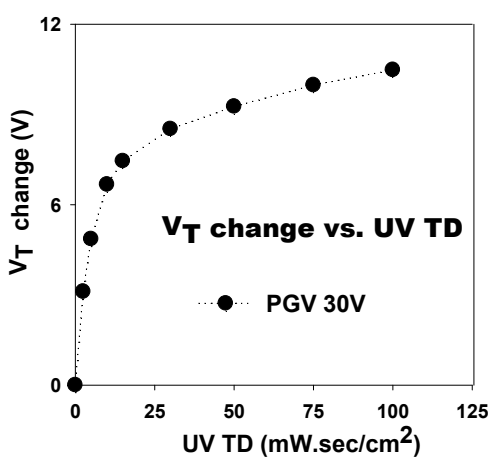

(a)

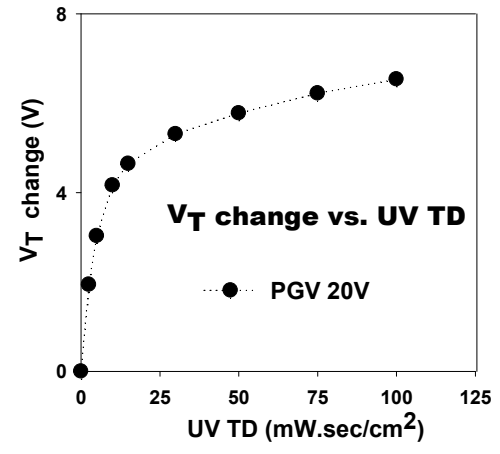

(b)

Figure 4. The dependence of the UV-induced $V_{T}$ increase on UV TD for an SAHAOS-T3 capacitor (a) at PGV $30 \mathrm{~V} ;(\mathbf{b})$ at PGV $20 \mathrm{~V}$.

Figure 5a shows a comparison of $\mathrm{V}_{\mathrm{T}}$ changes in the SAHAOS-T3 device after the fixed 100 $\mathrm{mW} \cdot \mathrm{s} / \mathrm{cm}^{2} \mathrm{UV}$ TD irradiation at different PGVs. In Table 3, a list of symbols for various UV and PGV conditions on the SAHAOS-T3 device is listed. Under UV TD $100 \mathrm{~mW} \cdot \mathrm{s} / \mathrm{cm}^{2}$ irradiation, the $V_{T}$ change of SAHAOS-T3 is very significant at PGV $30 \mathrm{~V}$ compared to those at different PGVs under UV TD $100 \mathrm{~mW} \cdot \mathrm{s} / \mathrm{cm}^{2}$ irradiation, as shown in Figure 5a. It is noted that even with $100 \mathrm{~mW} \cdot \mathrm{s} / \mathrm{cm}^{2} \mathrm{UV}$ TD irradiation, the $\mathrm{V}_{\mathrm{T}}$ change of SAHAOS-T3 at $5 \mathrm{~V} \mathrm{PGV}$ is very small compared to the those at different PGVs, as shown in Figure 5a. 


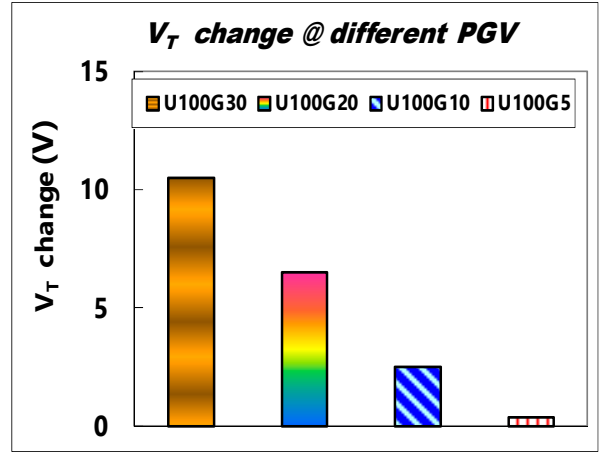

(a)

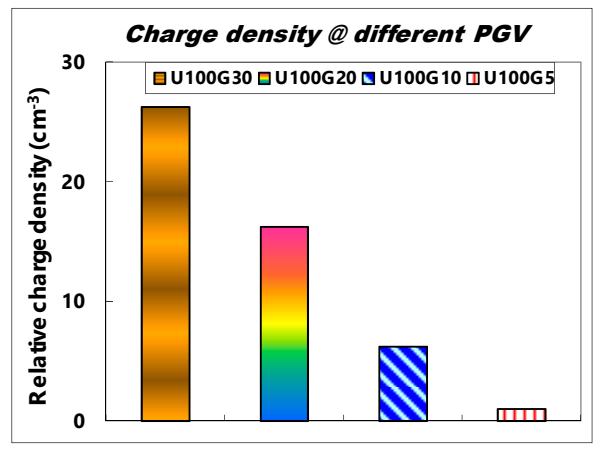

(c)

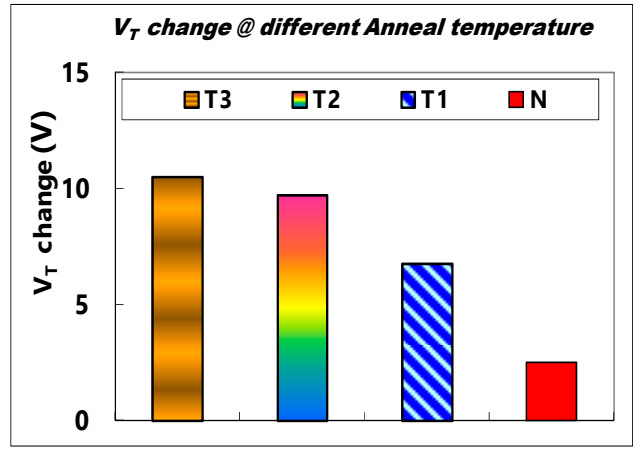

(b)

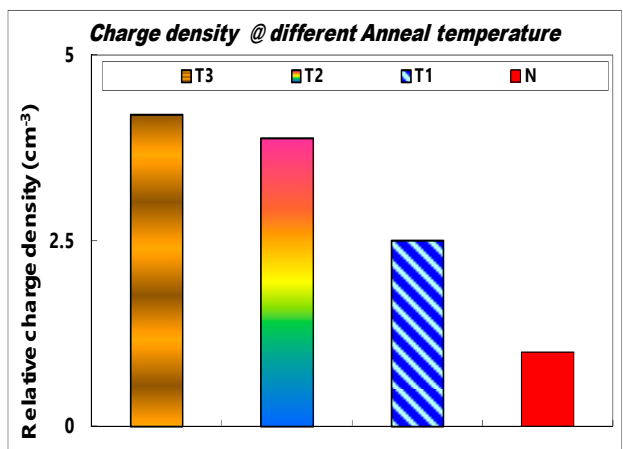

(d)

Figure 5. (a) The UV-induced $\mathrm{V}_{\mathrm{T}}$ change comparison of SAHAOS-T3 capacitor devices at different PGVs after $100 \mathrm{~mW} \cdot \mathrm{s} / \mathrm{cm}^{2} \mathrm{UV}$ TD irradiation; (b) the UV-induced $\mathrm{V}_{\mathrm{T}}$ change comparison for various SAHAOS and SONOS capacitor devices with different PMA temperatures after the U100G30 irradiation condition; (c) the relative UV-induced charge density comparison of SAHAOS-T3 capacitor devices at different PGVs after $100 \mathrm{~mW} \cdot \mathrm{s} / \mathrm{cm}^{2}$ UV TD irradiation; (d) the relative UV-induced charge density comparison for various SAHAOS and SONOS capacitor devices with different PMA temperatures after the U100G30 irradiation condition.

Figure $5 c$ shows the relative charge density comparison of SAHAOS-T3 devices after $100 \mathrm{~mW} \cdot \mathrm{s} / \mathrm{cm}^{2} \mathrm{UV}$ TD irradiation at different PGVs. It is worth noting that, as shown in Figure $5 \mathrm{c}$, the UV-induced charge density of SAHAOS-T3 at PGV $30 \mathrm{~V}$ is almost 25 times greater than that at PGV $5 \mathrm{~V}$ under UV TD $100 \mathrm{~mW} \cdot \mathrm{s} / \mathrm{cm}^{2}$ illumination. As shown in Figure $5 \mathrm{a}$, the change in $\mathrm{V}_{\mathrm{T}}$ of the SAHAOS-T3 device is negligible only under UV illumination in the absence of PGV. By applying different PGVs during the UV illumination, the sensitivity of the SAHAOS devices is adjustable, which makes them suitable for various applications.

Figure $5 b$ shows a comparison of the $V_{T}$ change for various SAHAOS devices with different PMA temperatures after the U100G30 irradiation condition. Table 2 shows a list of symbols for SAHAOS devices prepared with various PMA temperatures. It is important to note that, under the U100G30 irradiation condition, the UV-induced $\mathrm{V}_{\mathrm{T}}$ changes of SAHAOS-T3 and SAHAOS-T2 are very significant compared to those of SAHAOS-T1 and STD-SAONOS, as shown in Figure 5b. Figure 5d shows the relative UV-induced charge density for various SAHAOS and STD-SANOS devices with different PMA temperatures after the U100G30 irradiation condition. Under the U100G30 irradiation condition, it is noted that the UV-induced $V_{\mathrm{T}}$ change of SAHAOS-T3 with $1100{ }^{\circ} \mathrm{C} 5 \mathrm{~s}$ PMA is almost four times greater than that of STD-SANOS with $900{ }^{\circ} \mathrm{C} 30 \mathrm{~s}$ PMA. Meanwhile, the UV-induced $\mathrm{V}_{\mathrm{T}}$ change of the SAHAOS-T3 is almost two times that of the SAHAOS-T1 with $900{ }^{\circ} \mathrm{C} 30 \mathrm{~s}$ PMA under the U100G30 irradiation condition. Moreover, the UV-induced $V_{T}$ change of SAHAOS-T3 with $1100{ }^{\circ} \mathrm{C}$ 
$5 \mathrm{~s}$ PMA is almost 1.1 times SAHAOS-T2 with the $1000{ }^{\circ} \mathrm{C} 30 \mathrm{~s}$ PMA under U100G30 irradiation, as shown in Figure 5b. It is also noted that the UV-induced charge density of SAHAOS-T3 with $1100{ }^{\circ} \mathrm{C}$ $5 \mathrm{~s}$ PMA is almost eight times greater than that of STD-SANOS with $900{ }^{\circ} \mathrm{C} 30 \mathrm{~s}$ PMA under the U100G30 irradiation condition. The SAHAOS-T3 and SAHAOS-T2 both demonstrate higher degrees of UV-induced $V_{T}$ shift and UV-induced charge density than the SAHAOS-T1 and STD-SANOS devices.

An X-ray diffraction (XRD) analysis comparison of HfAlO films with different PMA temperatures is shown in Figure 6a. The XRD analysis shows the temperature-dependent crystallization of HfAlO, as presented in Figure 6a. A transmission electron microscopy (TEM) comparison of HfAlO films with different PMA temperatures is shown in Figure $6 \mathrm{~b}-\mathrm{d}$. It can be seen from the XRD and TEM results that the HfAlO film is almost still amorphous, even after annealing at $900{ }^{\circ} \mathrm{C} 30 \mathrm{~s}$, and is partially nano crystallized after annealing at both $1000^{\circ} \mathrm{C} 30 \mathrm{~s}$ and $1100{ }^{\circ} \mathrm{C} 5 \mathrm{~s}$. Further, it seems that the $\mathrm{HfAlO}$ film annealed at $1100{ }^{\circ} \mathrm{C}$ for $5 \mathrm{~s}$ has a larger number of partial nanocrystals than the $\mathrm{HfAlO}$ film annealed at $1000{ }^{\circ} \mathrm{C}$ for $30 \mathrm{~s}$, as shown in Figure 6. The Al composition ratios in HfAlO of SAHAOS-T3, SAHAOS-T2, and SAHAOS-T1 devices are all the same, with a value of about $30 \%$ in this study. The trap density of the $\mathrm{HfO}_{2}$ trap layer of the SOHOS device can be increased by doping a suitable $\mathrm{Al}$ content into the $\mathrm{HfO}_{2}$ charge trap layer [8-13].

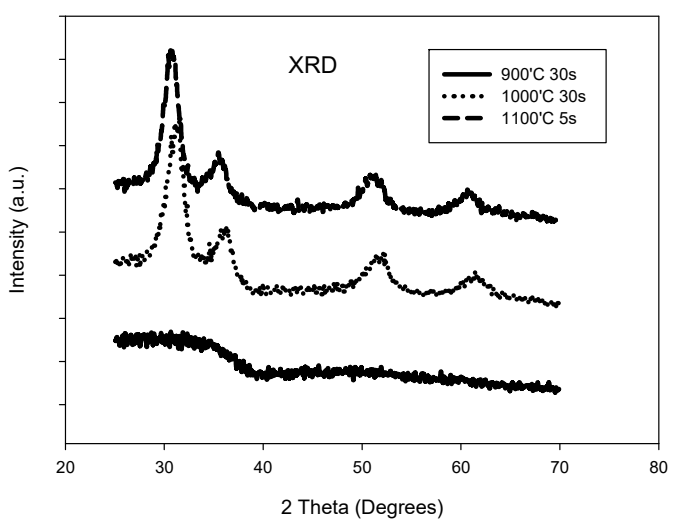

(a)

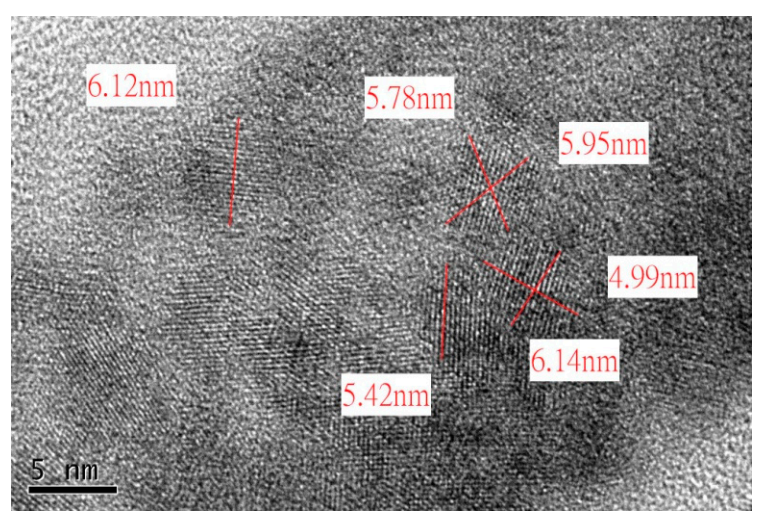

(c)

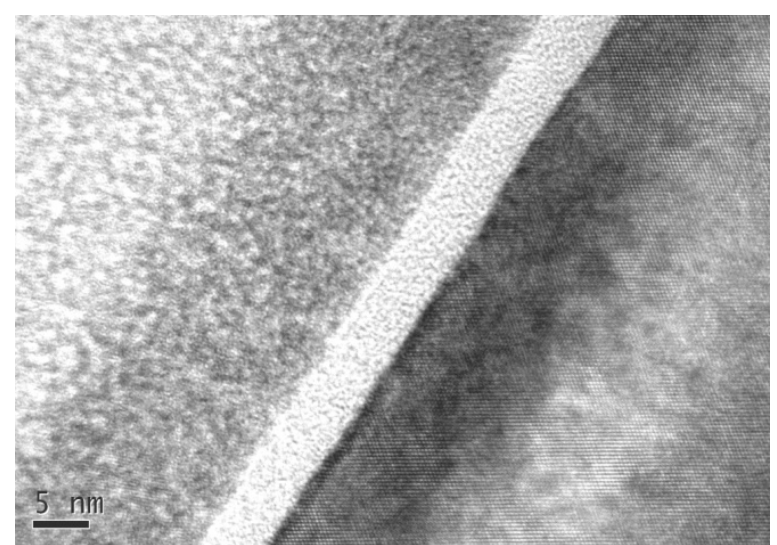

(b)

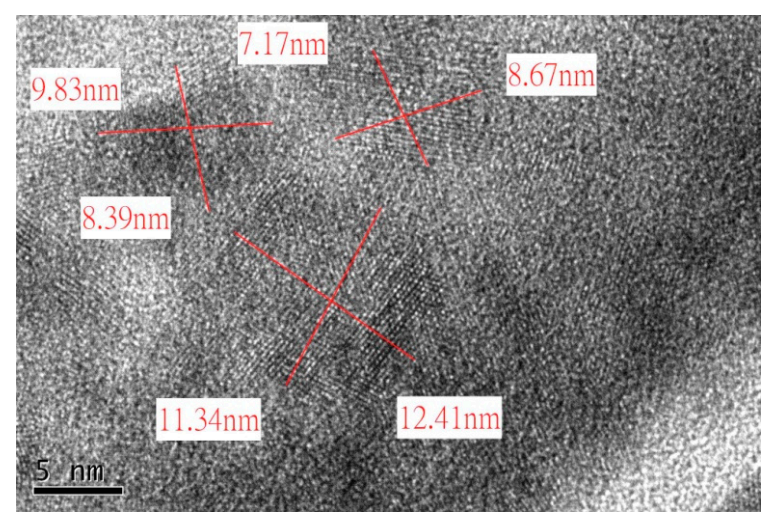

(d)

Figure 6. (a) XRD analysis comparison of HfAlO films with different anneal temperatures; (b) TEM image of SAHAOS capacitor with $900{ }^{\circ} \mathrm{C} 30 \mathrm{~s}$ PMA; (c) TEM image of SAHAOS capacitor with $1000{ }^{\circ} \mathrm{C}$ 30 s PMA; (d) TEM image of SAHAOS capacitor with $1100{ }^{\circ} \mathrm{C} 5 \mathrm{~s}$ PMA.

\subsection{Gate Leakage Current Comparison}

The $\mathrm{I}_{\mathrm{G}}-\mathrm{V}_{\mathrm{G}}$ curves for a SAHAOS-T3 capacitor device before and after the U100G30 irradiation condition are shown in Figure 7a,b, respectively. As demonstrated in Figure 7a,b, the gate oxide 
leakage current at PGV $30 \mathrm{~V}$ for the SAHAOS-T3 capacitor device did not increase significantly after the U100G30 irradiation condition.

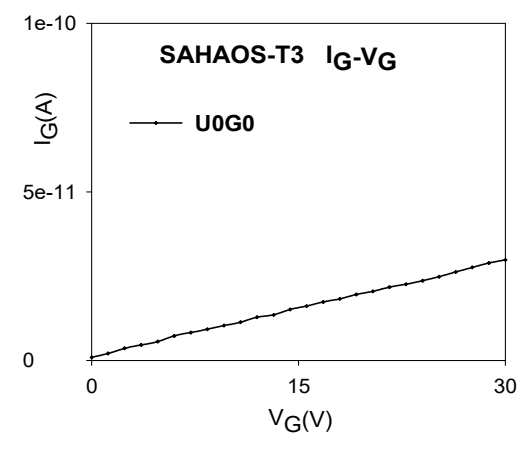

(a)

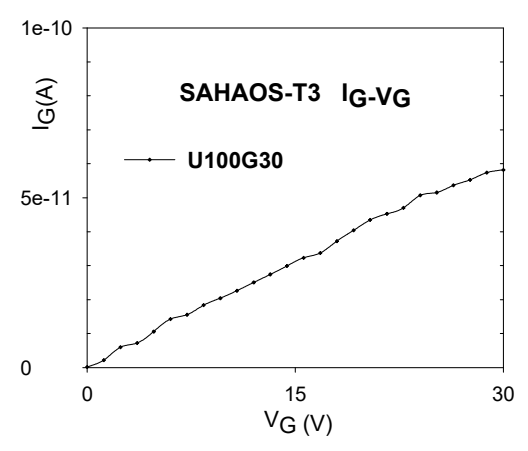

(b)

Figure 7. The gate leakage current at PGV $30 \mathrm{~V}$ for an SAHAOS-T3 capacitor device (a) before UV irradiation; (b) after U100G30 irradiation.

Figure 8a shows the comparison of $\mathrm{I}_{\mathrm{G}}$ at $\mathrm{V}_{\mathrm{G}}=30 \mathrm{~V}$ for various SAHAOS with different PMA temperatures before UV irradiation. Figure $8 \mathrm{~b}$ demonstrates the comparison of $\mathrm{I}_{\mathrm{G}}$ at $\mathrm{V}_{\mathrm{G}}=30 \mathrm{~V}$ for various SAHAOS with different PMA temperatures after UV TD $100 \mathrm{~mW} \cdot \mathrm{s} / \mathrm{cm}^{2}$ irradiation. As illustrated in Figure 8a,b, the gate dielectric leakage current of the SAHAOS-T3 and SAHAOS-T2 devices at $\mathrm{V}_{\mathrm{G}}=30 \mathrm{~V}$ before and after UV irradiation is significantly improved compared to the SAHAOS-T1 and STD-SANOS devices.

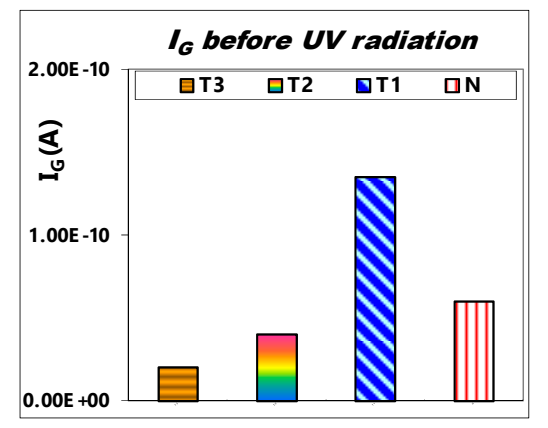

(a)

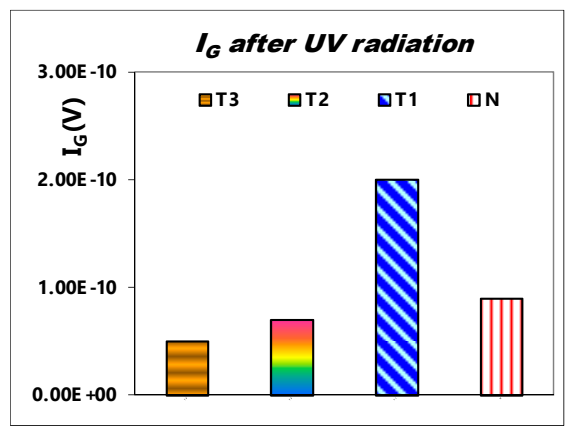

(b)

Figure 8. (a) The gate-current comparison at $\mathrm{V}_{\mathrm{G}} 30 \mathrm{~V}$ for various SAHAOS with different PMA temperatures before the UV irradiation condition; (b) The gate-current at $V_{G} 30 \mathrm{~V}$ for various SAHAOS with different PMA temperatures after the U100G30 irradiation condition.

\section{3. $V_{T}$ Stability vs. Retention Time}

The $\mathrm{V}_{\mathrm{T}}$ room temperature retention characterization for an SAHAOS-T3 device before and after the U100G30 irradiation condition is demonstrated in Figure 9a,b, respectively. As shown in Figure 9a, before UV irradiation, the native negative charge naturally tunnels to the HfAlO capture layer, and the $\mathrm{V}_{\mathrm{T}}$ of the SAHAOS-T3 device increases with time. As shown in Figure 9b, after UV irradiation, the UV-induced negative charge escapes from the HfAlO capture layer, and the $\mathrm{V}_{\mathrm{T}}$ of the SAHAOS-T3 device decreases over time [5,6]. In addition, the $\mathrm{V}_{\mathrm{T}}$ retention loss of the SAHAOS-T3 device is less than $5 \%$ after 10 years of retention. 


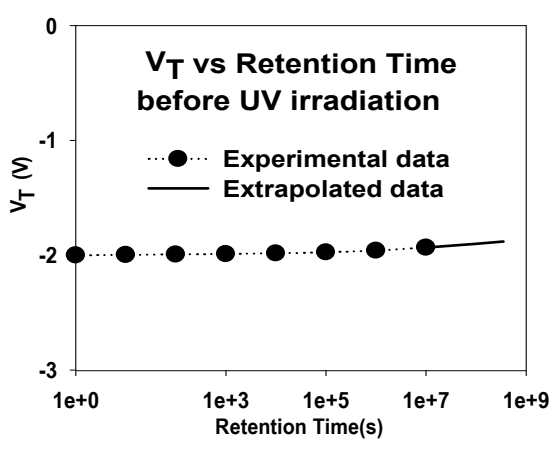

(a)

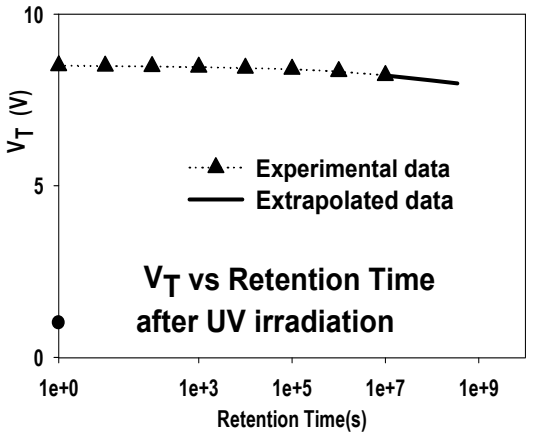

(b)

Figure 9. The $\mathrm{V}_{\mathrm{T}}$ room temperature retention characterization curve for an SAHAOS-T3 device: (a) before UV irradiation; and (b) after U100G30 irradiation.

Figure $10 \mathrm{a}, \mathrm{b}$ illustrate the comparison of the $25^{\circ} \mathrm{C}$ charge retention characteristics of 10 years for various SAHAOS devices with different PMA temperatures before UV irradiation and after U100G30 irradiation. As illustrated in Figure 10a,b, the $25^{\circ} \mathrm{C}$ charge 10 -year retention performances of the PNC-SAHAOS (SAHAOS-T3, SAHAOS-T2) devices are significantly better than that of the SAHAOS-T1 device.

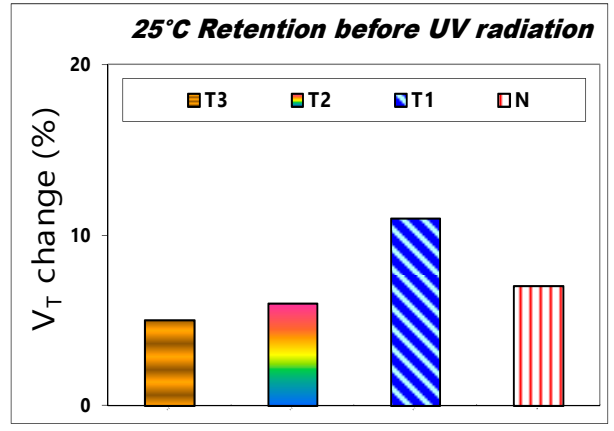

(a)

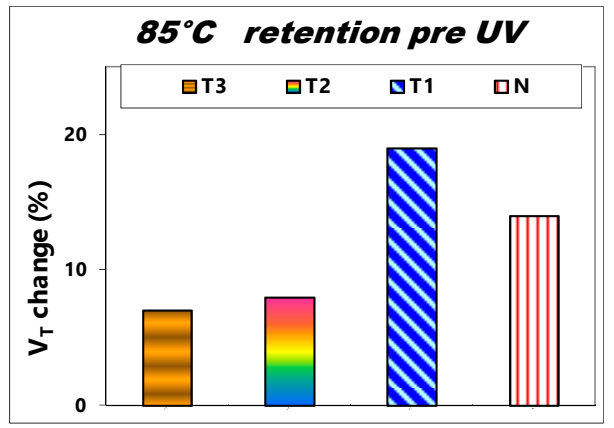

(c)

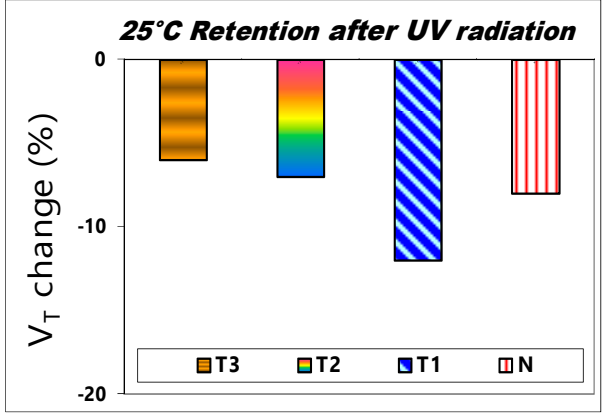

(b)

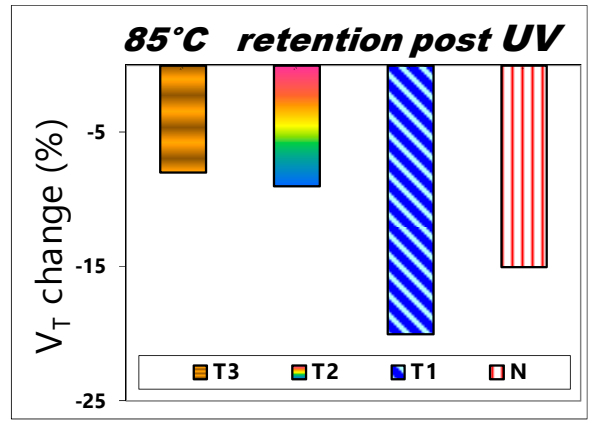

(d)

Figure 10. The comparison of $\mathrm{V}_{\mathrm{T}}$ change after a 10-years retention for various $S A H A O S$ and SANOS with different PMA temperatures (a) before UV irradiation at $25^{\circ} \mathrm{C} ;(\mathbf{b})$ after UV100G30 irradiation at $25^{\circ} \mathrm{C}$; (c) before UV irradiation at $85^{\circ} \mathrm{C}$; (d) after UV100G30 irradiation at $85^{\circ} \mathrm{C}$.

The $85^{\circ} \mathrm{C} 10$-year charge retention reliability properties of comparison for various SAHAOS and SANOS devices are shown in Figure 10c,d. The PNC-SAHAOS device had good charge retention at $25^{\circ} \mathrm{C}$ and $85^{\circ} \mathrm{C}$, and no significant charge loss/gain was observed. However, the SANOS device only exhibits good charge retention at $25^{\circ} \mathrm{C}$, but exhibits poor charge retention and significant charge 
loss/gain at $85^{\circ} \mathrm{C}$. The PNC-SAHAOS device had good charge retention at different temperatures in comparison with the SANOS device, which could not act properly at higher temperatures.

\subsection{Model for UV-Induced $V_{T}$ Shift}

In order to simulate the $\mathrm{V}_{\mathrm{T}}$ shift of SAHAOS devices after $\mathrm{UV}$ radiation, the author proposed a model (hereafter called HWC-UV model) derived from the prior studies of the HWC model [14]. The HWC-UV model is used to simulate the $\mathrm{V}_{\mathrm{T}}$ shift of a SAHAOS-T3 device after various UV TD irradiation at different PGVs, and the formula for the model is as follows:

$$
\operatorname{delta} V_{T}(D)=V_{T}(D)-V_{T}(0)=\left[\left(V_{G}-V_{o}\right) / A\right] \log \left(t^{*} D\right)
$$

In this equation, D represents the UV TD $\left(\mathrm{mW} \cdot \mathrm{s} / \mathrm{cm}^{2}\right), \mathrm{V}_{\mathrm{T}}(\mathrm{D})$ is the $\mathrm{V}_{\mathrm{T}}$ after UV TD irradiation, $\mathrm{V}_{\mathrm{T}}(0)$ is the $\mathrm{V}_{\mathrm{T}}$ before $\mathrm{UV}$ radiation, and $\mathrm{V}_{\mathrm{G}}$ is the PGV. The author used experimental curve fitting to derive the three parameters $V_{0}, t$, and A of the HWC-UV model. $t$ is the sum of emission and capture constant of electrons and holes. $V_{o}$ and $A$ are the constants for specific devices. $V_{o}$ is the minimum PGV for $U V$-induced $V_{T}$ shifting. When $V_{G}$ is smaller than $V_{o}$, the insufficient electric field can not separate the UV-induced electron-hole pairs and inject the UV-induced charges over the $\mathrm{Si}_{-} \mathrm{SiO}_{2}$ potential barrier into the AHAOS gate dielectric layer from the silicon substrate. A is the charge capture constant for specific devices. $V_{o}$ is equal to 4 Volt, $t$ is equal to $3 \mathrm{~cm}^{2} / \mathrm{mW} \cdot \mathrm{s}$, and $A$ is equal to 6 for SAHAOS-T3 devices in this study. They are the optimum fitting parameters to predict the UV-induced delta $\mathrm{V}_{\mathrm{T}}(\mathrm{D})$ of the SAHAOS-T3 device. Using these optimum fitting parameters, the simulated $\mathrm{V}_{\mathrm{T}}$ shift after various UV TD radiation at different PGVs can be predicted using Equation (1).

The comparisons of the measured and simulated curves of the $\mathrm{V}_{\mathrm{T}}$ shift verus UV TD for SAHAOS-T3 devices under four fixed PGVs are shown in Figure 11a-d. Please note that the HWC-UV model can simulate all experimental curves very well, as shown in Figure 11.

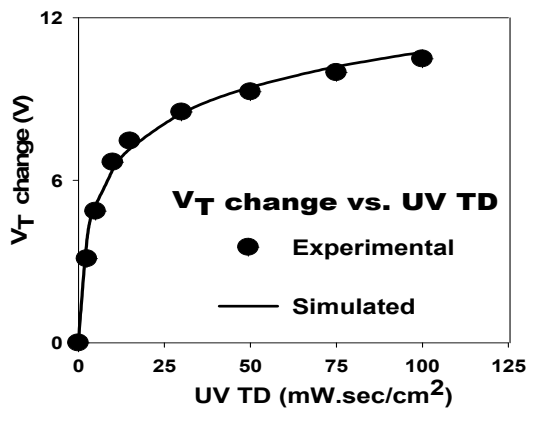

(a)

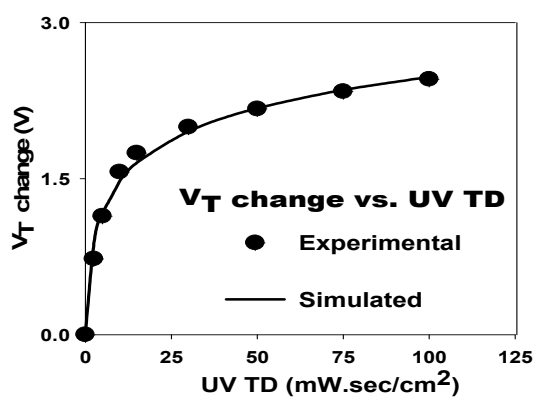

(c)

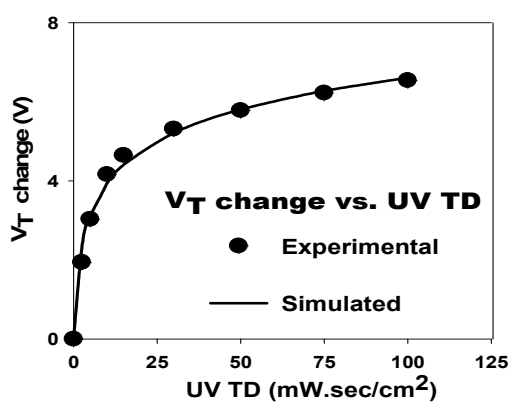

(b)

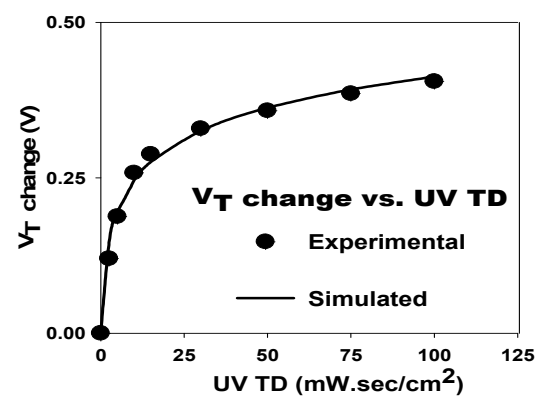

(d)

Figure 11. The model of $\mathrm{V}_{\mathrm{T}}$ change as a function of UV TD for an SAHAOS-T3 capacitor device (a) under PGV 30 V; (b) under PGV 20 V; (c) under PGV 10 V; (d) under PGV 5 V. 
Figure 12 is a comparison of the measured and simulated curves of the $V_{T}$ shift verus PGV at fixed UV TD for a SAHAOS-T3 capacitor device, and the delta $\mathrm{V}_{\mathrm{T}}$ is almost a linear function of PGV during fixed UV TD irradiation for an SAHAOS-T3 capacitor device. Figure 12 shows that the HWC-UV model can predict the curves of $\mathrm{V}_{\mathrm{T}}$ shift verus PGV under fixed UV TD well.

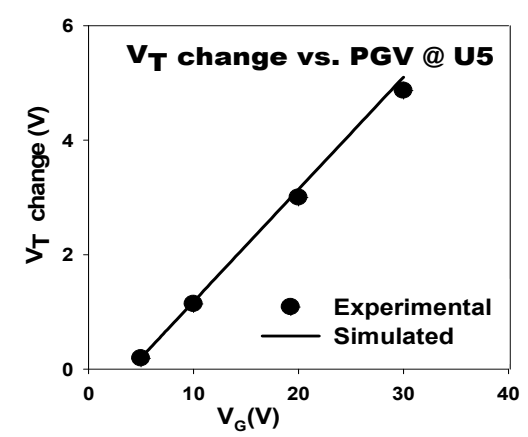

(a)

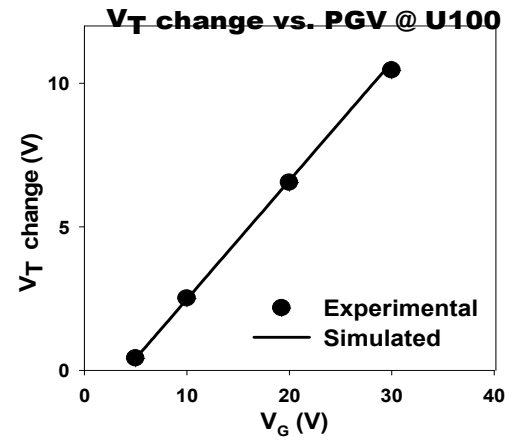

(b)

Figure 12. The model of $\mathrm{V}_{\mathrm{T}}$ as a function of PGV under fixed UV TD for an SAHAOS-T3 capacitor device (a) under UV TD $5 \mathrm{~mW} \cdot \mathrm{s} / \mathrm{cm}^{2}$ irradiation; (b) under UV TD $100 \mathrm{~mW} \cdot \mathrm{s} / \mathrm{cm}^{2}$ irradiation.

\section{Discussion}

\subsection{UV-Induced $V_{T}$ Shift in SAHAOS}

As illustrated in Figure $3 \mathrm{a}, \mathrm{b}$, the positive $\mathrm{V}_{\mathrm{T}}$ shiftting is due to the increase in the net total UV-induced negative trapped charge accumulated in the AHAO gate dielectric layer after UV illumination at PGV. This positive $\mathrm{V}_{\mathrm{T}}$ shift result is consistent with previous studies $[5,6]$. It is worth noting that the $100 \mathrm{~mW} \cdot \mathrm{s} / \mathrm{cm}^{2}$ TD UV leads to a significant increase in the $\mathrm{V}_{\mathrm{T}}$ for the SAHAOS-T3 at $30 \mathrm{~V}$ PGV by about 10.5 volts. Higher UV TD contributes to the accumulation of carriers in the inversion layer. Under UV irradiation, the applied PGV drops at the AHAO dielectric, and the density of injected electrons from the inversion layer is sufficient to cause a huge number of electrons in the AHAO trapping layer, causing the $\mathrm{V}_{\mathrm{T}}$ to shift to the right.

As illustrated in Figure 5a,c, the sensitivity of SAHAOS devices is tunable by adjusting different PGVs during irradiation, which makes them suitable for various applications. For increasing PGV, there is an increase in the charge yield corresponding to a decrease in the initial recombination of UV-induced electron-hole pairs, which will tend to increase the amount of UV-induced voltage shift [7].

As illustrated in Figure 5b, the UV-induced charging responses of the SAHAOS devices with $1000{ }^{\circ} \mathrm{C} 30 \mathrm{~s}$ and $1100^{\circ} \mathrm{C} 5 \mathrm{~s}$ PMA have been significantly improved, compared with the SAHAOS with $900{ }^{\circ} \mathrm{C}$ PMA and STD-SANOS devices with $900{ }^{\circ} \mathrm{C}$ PMA. Therefore, the author thinks that that the partially nanocrystallized HfAlO (hereafter PNC-HfAlO) trapping layer has a larger trap density than the amorphous $\mathrm{HfAlO}$ and $\mathrm{Si}_{3} \mathrm{~N}_{4}$ trapping layer. A discrete nanocrystal structure was formed by the partial crystallization of $\mathrm{HfAlO}$ using the PMA process at $100{ }^{\circ} \mathrm{C} 30 \mathrm{~s}$ and $1100{ }^{\circ} \mathrm{C} 5 \mathrm{~s}$. However, in the partially nanocrystallized HfAlO trapping layer, HfAlO nanocrystals are embedded in amorphous HfAlO. UV-induced charges can be trapped not only in HfAlO nanocrystals, but also in amorphous regions of the HfAlO trapping layer. Therefore, it is understood that the partially nanocrystallized HfAlO trapping layer has a higher trap density than the complete amorphous HfAlO trapping layer [15-20]. The author thinks that that the nanocrystallization-induced trap generation enhances the trap density. Therefore, the SAHAOS-T3 and SAHAOS-T2 (hereafter PNC-SAHAOS) with a PNC-HfAlO trapping layer show a larger trap density compared to SAHAOS-T1 with an amorphous HfAlO trapping layer [15-20]. 


\subsection{Gate Leakage Current Comparison}

As illustrated in Figure 8a,b, the gate dielectric leakage current of the SAHAOS-T3 and SAHAOS-T2 devices at $\mathrm{V}_{\mathrm{G}}=30 \mathrm{~V}$ before and after $\mathrm{UV}$ irradiation has been significantly improved, compared with the SAHAOS-T1 and STD-SANOS device. Therefore, the author believes that the HfAlO nanocrystals highly capture localized charges and effectively suppress lateral charge migration, which can act as current leakage paths [15-20].

\section{3. $V_{T}$ Stability vs Retention Time}

As illustrated in Figure 10a,b, the $25{ }^{\circ} \mathrm{C}$ charge 10-years retention performances of the PNC-SAHAOS (SAHAOS-T3, SAHAOS-T2) devices are significantly better than that of the SAHAOS-T1 device. This is because the HfAlO charge-storage layer of SAHAOS-T1 is still relatively amorphous, while the HfAlO charge-storage layers of PNC-SAHAOS have already been partially nanocrystallized. The partially nanocrystallized HfAlO thin films of PNC-SAHAOS will capture highly localized charges and effectively inhibit the charge leakage path. Hence, for PNC-SAHAOS, there will be a decrease in the charge leakage path of HfAlO films, which can result in better charge retention [15-20].

The PNC-SAHAOS device had good charge retention at different temperatures in comparison with the SANOS device that cannot act properly at higher temperatures. The charge retention performance of the PNC-HfAlO charge storage layer is significantly improved compared to that with amorphous $\mathrm{Si}_{3} \mathrm{~N}_{4}$ and amorphous HfAlO in this paper, which is likely attributed to the partially crystallized HfAlO suppressed lateral charge migration. The partially nanocrystallized HfAlO thin films of PNC-SAHAOS will capture highly localized charges and effectively inhibit the charge leakage path. Hence, for PNC-SAHAOS, there will be a decrease in the charge leakage path of HfAlO films, which can result in better charge retention [15-20]. In the partially crystallized HfAlO trapping layers, nanocrystals are embedded in amorphous HfAlO; thus, injected electrons can be trapped in HfAlO nanocrystals and the amorphous HfAlO matrix. The structure with nanocrystals embedded in an amorphous dielectric matrix could suppress lateral charge migration. The partially nanocrystallized HfAlO thin films of PNC-SAHAOS will capture highly localized charges and effectively inhibit the charge leakage path. Hence, for PNC-SAHAOS, there will be a decrease in the charge leakage path of HfAlO films, which can result in better charge retention. Moreover, the improvement of charge-retention performance is primarily due to the annihilation of shallower charge traps and increase of deeper charge traps in the HfAlO trapping layer. The PNC-SAHAOS devices with deeper charge traps in the PNC-HfAlO trapping layer showed better charge-retention reliability characteristics than the SAHAOS-T1 and SANOS devices with shallower charge traps in the amorphous $\mathrm{HfAlO}$ and $\mathrm{Si}_{3} \mathrm{~N}_{4}$ trapping layer.

\section{Conclusions}

Compared with traditional UV intensity sensing elements, the SOHOS-type non-volatile UV TD sensor has the following advantages: (1) Small size and light weight; (2) good correlation between accumulated UV-inductive charge and UV TD; (3) UV TD recording can be permanently accumulated in the device; (4) UV TD recording can be erased; (5) devices with high-k technology can be integrated into the next generation IC chip; (6) data reading equipment is simple and convenient; and (7) the sensitivity of a UV TD sensor is adjustable [6].

The UV-induced charging response and the charge retention characteristics of the PNC-SAHAOS capacitor devices with $1000^{\circ} \mathrm{C}$ and $1100^{\circ} \mathrm{C}$ PMA have been significantly improved, compared with the amorphous SAHAOS-T1 and SANOS devices with $900{ }^{\circ} \mathrm{C}$ PMA. The PNC-HfAlO charge storage layer containing nanocrystals formed in an amorphous HfAlO matrix shows both crystalline and amorphous HfAlO properties. UV-induced charges can be trapped not only in nanocrystals, but also in amorphous matrices. Therefore, the author thinks that the PNC-HfAlO trapping layer has a larger trap density than the amorphous $\mathrm{HfAlO}$ and $\mathrm{Si}_{3} \mathrm{~N}_{4}$ trapping layer. Furthermore, the author considers that 
the PNC-HfAlO trapping layer has suppressed lateral charge migration compared to the amorphous $\mathrm{Si}_{3} \mathrm{~N}_{4}$ and HfAlO trapping layer. It is true that a higher PMA temperature $\left(>90{ }^{\circ} \mathrm{C}\right)$ is necessary to form the high- $\mathrm{K}$ Hf-based PNC-HfAlO to enhance the nonvaltile UV TD sensor performance in this paper. These results strongly suggest that $\mathrm{PNC}-\mathrm{HfAlO}$ is a promising charge-trapping structure for next-generation nonvolatile SONOS-type UV TD sensor technology.

Author Contributions: The presented work is a product of W.-C.H. W.-C.H. initiated the research idea and performed all the experiments. W.-C.H. drafted the manuscript for review.

Funding: This paper was funded in part by the National Science Council (NSC) sponsor.

Acknowledgments: The author would also like to thank National Nano Device Laboratories (NDL), National Tsing Hua University (NTHU), and National Chiao Tung University (NCTU) for providing the instruments for wafer fabrication and testing. This paper was funded in part by the National Science Council (NSC) sponsor.

Conflicts of Interest: The author declares no conflict of interest.

\section{References}

1. Sze, S.M.; Ng, K.K. Physics of Semiconductor Devices, 3rd ed.; John Wiley \& Sons: Hoboken, NJ, USA, 2006; p. 663.

2. Hsieh, W.C.; Su, C.S. UV induced thermoluminescence in $\mathrm{ZrO}_{2}$ doped by $\mathrm{Er}_{2} \mathrm{O}_{3}$. J. Phys. D Appl. Phys. 1994, 27, 1763-1768. [CrossRef]

3. Pejović, M.M. P-channel MOSFET as a sensor and dosimeter of ionizing radiation. Electron. Energ. 2016, 29, 509-541. [CrossRef]

4. Ho, W.S.; Lin, C.-H.; Kuo, P.-S. Metal Oxide Semiconductor UV Sensor. Proc. IEEE Sens. 2008, 1584-1587. [CrossRef]

5. Jong, F.C.; Hsieh, W.C.; Lee, H.D.; Wu, S.C. UV Total Dose Nonvolatile Sensor Using Silicon-Oxide-Nitride-Oxide-Silicon Capacitor with Oxy-nitride as Charge-trapping Layer. Sens. Mater. 2018, 30, 1831-1839. [CrossRef]

6. Hsieh, W.C. UV Total Dose Nonvolatile Sensor Using Fluorine-Treated SOHOS Capacitor Device. Proceedings 2018, 2, 144. [CrossRef]

7. Oldham, T.R.; McLean, F.B. Total Ionizing Dose Effects in MOS Oxides and Devices. IEEE Trans. Nucl. Sci. 2003, 50, 483-499. [CrossRef]

8. Tsai, P.H.; Chang-Liao, K.S.; Liu, C.Y.; Wang, T.K.; Tzeng, P.J.; Lin, C.H.; Lee, L.S.; Tsai, M.J. Novel SONOS-Type Nonvolatile Memory Device with Optimal Al Doping in HfAlO Charge-Trapping Layer. IEEE Electron. Device Lett. 2008, 29, 265-268. [CrossRef]

9. Tan, Y.N.; Chim, W.K.; Choi, W.K.; Joo, M.S.; Ng, T.H.; Cho, B.J. High-K HfAlO Charge Trapping Layer in SONOS-type Nonvolatile Memory Device for High Speed Operation. IEEE IEDM 2004, 04, 889-892.

10. Yu, H.Y.; Li, M.F.; Kwong, D.L. ALD $\left(\mathrm{HfO}_{2}\right)_{x}\left(\mathrm{Al}_{2} \mathrm{O}_{3}\right)_{-1 x}$ high-k gate dielectrics for advanced MOS devices application. Thin Solid Films 2004, 462, 110-113. [CrossRef]

11. Zhu, W.J.; Tamagawa, T.; Gibson, M.; Furukawa, T.; Ma, T.P. Effect of $\mathrm{Al}$ Inclusion in $\mathrm{HfO}_{2}$ on the Physical and Electrical Properties of the Dielectrics. IEEE Electr. Device Lett. 2002, 23, 649-651. [CrossRef]

12. Tan, Y.N.; Chim, W.K.; Choi, W.K.; Joo, M.S.; Cho, B.J. Hafnium Aluminum Oxide as Charge Storage and Blocking-Oxide Layers in SONOS-Type Nonvolatile Memory for High-Speed Operation. IEEE Trans. Electron. Devices 2006, 53, 654-662. [CrossRef]

13. Zhu, W.; Ma, T.P.; Tamagawa, T.; Di, Y.; Kim, J.; Carmthers, R.; Gibson, M.; Furukawa, T. $\mathrm{HfO}_{2}$ and HfAlO for CMOS: Thermal Stability and Current Transport. IEEE IEDM 2001, 1, 463-466.

14. Hsieh, W.C.; Lee, H.D.; Jong, F.C. An Ionizing Radiation Sensor Using a Pre-Programmed MAHAOS Device. Sensors 2014, 14, 14553-14566. [CrossRef]

15. Zhang, G.; Samanta, S.K.; Singh, P.K.; Ma, F.J.; Yoo, M.T.; Roh, Y.; Yoo, W.J. Partial Crystallization of HfO2 for Two-Bit/Four-Level SONOS-Type Flash Memory. IEEE Trans. Electron. Devices 2007, 54, 3177-3185. [CrossRef]

16. Lin, Y.H.; Chien, C.H.; Chang, C.Y.; Lei, T.F. Annealing temperature effect on the performance of nonvolatile $\mathrm{HfO}_{2}$ Si-oxide-nitride-oxide-silicon-type flash memory. J. Vac. Sci. Technol. A Vac. Surf. Films 2006, 24, 682-685. [CrossRef] 
17. Wakai, H.; Sugizaki, T.; Kumise, T.; Kobayashi, M.; Yamaguchi, M.; Nakanishi, T.; Tanaka, H. Ultra high density $\mathrm{HfO}_{2}$-nanodot memory for flash memory scaling. Jpn. J. Appl. Phys. 2005, 45, 2459-2462. [CrossRef]

18. Banerjee, W.; Maikap, S. High-k Hf-based Nanocrystal Memory Capacitors with IrOx Metal Gate for NAND Application. In Proceedings of the 2009 IEEE International Workshop on Memory Technology, Design and Testing, Hsinchu, Taiwan, 31 August-2 September 2009.

19. Lin, Y.H.; Chien, C.H.; Lin, C.T.; Chang, C.Y. Novel Two-Bit $\mathrm{HfO}_{2}$ Nanocrystal Nonvolatile Flash Memory. IEEE Trans. Electron Devices 2006, 53, 782-789.

20. Sivasubramani, P.; Kim, J.; Kim, M.J.; Gnade, B.E.; Wallace, R.M. Effect of composition on the thermal stability of sputter deposited hafnium aluminate and nitrided hafnium aluminate dielectrics on Si (100). J. Appl. Phys. 2007, 101, 114108. [CrossRef]

(C) 2019 by the author. Licensee MDPI, Basel, Switzerland. This article is an open access article distributed under the terms and conditions of the Creative Commons Attribution (CC BY) license (http:/ / creativecommons.org/licenses/by/4.0/). 